Harvard Data Science Review • Issue 3.4, Fall 2021

\title{
Official Statistics from the \\ Changing World of Data \\ Science
}

\section{John Bailer ${ }^{1}$ Wendy Martinez $^{2}$}

${ }^{1}$ Department of Statistics, Miami University, Oxford, Ohio, United States of America,

${ }^{2}$ Bureau of Labor Statistics, Washington, District of Columbia, United States of America

Published on: Oct 28, 2021

DOI: https://doi.org/10.1162/99608f92.d0871196

License: Creative Commons Attribution 4.0 International License (CC-BY 4.0). 


\section{ABSTRACT}

Two events were held to answer questions regarding the future of official statistics. The first event took place on World Statistics Day 2020, whose theme was “What Is the Future of Official Statistics?” The second was a special session at the 63rd International Statistical Institute World Statistics Congress held in July 2021. Speakers and panelists who took part in both events were invited to contribute an article based on their talks to this special theme issue of HDSR.

Keywords: World Statistics Day, official statistics, national statistics offices, modernization

The idea for this special theme issue of Harvard Data Science Review (HDSR) started with a plenary talk given at the Joint Statistical Meetings (JSM) 2020. Dr. Erica Groshen, former Commissioner of the U.S. Bureau of Labor Statistics (BLS), gave the American Statistical Association (ASA) President's Invited Address in August 2020 at JSM where she addressed the question, “What Is the Future of Official Statistics?” Co-editor Wendy Martinez was ASA president who invited Dr. Groshen to present this talk. In case you missed it, you can view her talk here. Xiao-Li Meng, Editor-in-Chief of HDSR, invited Dr. Groshen to submit a paper to HDSR based on the transcript of her JSM talk.

Now, fast-forward to October 2020. The ASA, the Caucus for Women in Statistics, the International Statistical Institute (ISI), the International Association for Official Statistics (IAOS), and HDSR organized an event to celebrate World Statistics Day, which took place on October 20, 2020, or 20-10-2010 for ddmmyyyy dateformat fans. The theme in 2020 was "Connecting the World with Data We Can Trust." The World Statistics Day celebration was made official by the United Nations General Assembly in June of 2015. It was decided at that time to hold the event every five years on October 20. The first celebration happened in 2010 where the theme was "Service, Professionalism, Integrity: Celebrating the Many Contributions and Achievements of Official Statistics” (https://www.un.org/en/observances/statistics-day.).

The event started off with three speakers giving their perspectives. Ola Awad, President of the Palestinian Central Bureau of Statistics (PCBS), was the first to present. Her talk was followed by Erica Groshen giving an updated version of her JSM presentation. The session concluded with a talk from Wesley Yung, the Director of the Economic Analysis Division at Statistics Canada. We are thrilled to have articles from each of these authors in this special theme issue.

These three speakers joined other panelists for a discussion of the important ideas brought up in the talks. We were honored to have Sir Ian Diamond, the United Kingdom National Statistician, Rob Santos, the ASA 2021 president, and our co-editor John Bailer, then ISI president, as distinguished panelists and discussants. The event ended with John Pullinger, then IAOS president, giving an excellent and informative overview of the conversation. 
The World Statistics Day event motivated another one that took place at the 63rd ISI World Statistics Congress held in July 2021. Here, an invited panel session on "Official Statistics in the Changing World of Data Science” was organized. Panelists were asked to respond to the following questions:

1. What significant changes has the data science revolution brought, if any, to official statistics in your country/region/agency, in terms of both activities and planning?

2. What are the key challenges and opportunities as you see for official statistics in the digital age, especially with respect to data quality, including data collections and data privacy?

3. Do you think the advance of data science will make official statistics more or less independent from political interference, or broadly more or less trusted by the public?

4. What efforts are your government/agency making to recruit data scientists to work for official statistics? What kind of data scientists or data science skills do you particularly value?

5. What additional background, expertise, and skills do your staff need in light of this new data? How do you up-skill / conduct continuing professional education with current staff to address these needs?

Presenters and discussants from these two events were invited to contribute to the special topics section of this issue of $H D S R$.

The first paper in the special theme issue sets the stage for us. John Pullinger provides a summary highlighting the October 2020 World Statistics Day celebration and includes the important points brought up by the speakers. So, his paper "The Future of Federal Statistics: World Statistics Day Webinar - 20 October 2020" is a good starting point for readers.

Next, Ola Awad summarizes her talk in the article titled "Will Official Statistics Become Obsolete?" She describes the work the national statistical office in Palestine is doing regarding the modernization of official statistics. She makes the important point that the role of official statistics becomes even more important for effective policymaking as data become more available and accessible.

Ola's article is followed by Wesley Yung's paper, which continues the theme of modernization by national statistics offices, using the COVID-19 pandemic as context. He discusses the importance of providing official statistics that are trustworthy and of high quality. He defines various quality dimensions of data, such as accuracy, timeliness, relevance, accessibility, and interpretability. He presents some examples of modernization at Statistics Canada and describes how they relate to the quality dimensions. In conclusion, Wesley states that the future of statistics is bright and that national statistics offices have a critical role to play.

Erica Groshen continues the conversation in her article “The Future of Official Statistics.” Due to her former position as commissioner of the BLS, many of her examples pertain to the BLS and economics, but she also explores the COVID-19 pandemic on the practice of official statistics, as Wesley Yung does in his paper. She gives an overview of the U.S. federal statistical system—both past and present—-to provide important context 
for her remarks. Erica describes the importance of official statistics and why decision makers need them. She presents three paths forward: taking small incremental steps achieving minimal modernization, a downward spiral with further loss of public confidence and trust in official statistics, and a robust brighter future. Erica concludes with a call to action for statisticians and data scientists so we can realize the opportunities and achieve this brighter future.

Xiao-Li Meng and Liberty Vittert interviewed Ola Awad to learn more about the exciting work she is inspiring at the PCBS through their modernization efforts. Xiao-Li asked her to describe how the PCBS conducted their recent census and how they encouraged the public to respond. Ola briefly described a history of the census in Palestine, with the third and latest one taking place in 2017. The first two (1997 and 2007) were conducted using paper questionnaires and data recording. The PCBS decided to collect data in the 2017 census using handheld electronic devices that were linked with GIS (geographic information system). The PCBS worked with employees in the statistical office and with external stakeholders to educate and engage the public. We encourage our readers to read Ola’s interview for more details on the exciting things achieved by the PCBS.

The final article in this special theme issue is "Data Science and Official Statistics-Toward a New Data Culture” by Stefan Schweinfest and Ronald Jansen, both from the United Nations Statistics Division, Department of Economic and Social Affairs. Stefan and Ronald provide an excellent overview and many examples of national statistics offices' efforts to modernize through data science and computational statistics. A United Nations Committee of Experts on Big Data and Data Science was commissioned in 2014, which was tasked to advance a global vision to explore how data science can be used to improve official statistics. The authors echo statements made by Ola Awad in her article that national statistical offices must become data stewards to help a nation better manage their data resources. Other concerns brought up in this article include protecting data privacy, integrating data at geospatial and conceptual levels, establishing new job profiles that go beyond the classical statistician's duties, and providing continuous learning opportunities to stay abreast of current research.

We are honored to serve as co-editors of this special theme issue and are delighted that so many of the participants in the events described here opted to contribute a paper. This collection of articles brings up some important points regarding the future of official statistics, and we encourage you to be a part of the solution. We close with a quote from John Pullinger's article in this issue: "Let’s embrace this enormous opportunity with a strategy for federal statistics that is radical, ambitious, inclusive and sustainable.”

\section{Acknowledgments}

The authors would like to thank Xiao-Li Meng for his inspiration and support for not only this special theme issue but also for the two celebrations it summarizes. We also thank Rebecca McLeod for her patience and help keeping us on track with this special theme. It wasn’t an easy job. 


\section{Disclosure Statement}

John Bailer and Wendy Martinez have no financial or non-financial disclosures to share for this editorial.

(C)2021 John Bailer and Wendy Martinez. This editorial is licensed under a Creative Commons Attribution (CC BY 4.0) International license, except where otherwise indicated with respect to particular material included in the editorial. 